\title{
Research on College English Learning Model in Flipped Classroom on MOOC
}

\author{
Dan Li and Weina Ouyang* \\ Foreign Language Education Institute, Beihua University of Jilin 132000, China \\ Bettylidan@qq.com, 694839505@qq.com \\ * The corresponding author
}

Keywords: MOOC; Flipped classroom; Fixing learning model; Curriculum evaluation

\begin{abstract}
According to College English Teaching Guide's saying that teachers are encouraged to improve and exert teaching models with good-quality education resource online, the paper is about to carry out the theoretical analysis and experiment teaching with flipped classroom on MOOC which are more poplar domestic and overseas. The key is to research the model of learning, combing autonomic learning and cooperative learning which is more flexible, autonomic and diverse, fully displaying students' subjective initiative. Based on students' satisfaction and formative evaluation, college English curriculum evaluation is established to optimize the teaching under the model, which is beneficial and creative supplementary for college English teaching reform online.
\end{abstract}

\section{Introduction}

As illustrated in CECR 2004 aiming to enhancing individual learning formation and students' autonomic learning develop, teachers are encouraged to improve and exert teaching model with good-quality education resource online. Having been enforced for many years, college English reforms are still confined to class hours and language environment so that it is confronted with many obstacles such as information input and internal in-take, on the other hand, digital education reforms such as MOOC and Flipped Classroom become overwhelming. Therefore, the paper is based on MOOC and Flipped Classroom aiming to the current English level of students of provincial colleges and universities, optimize the learning models and evaluation, for cultivating students' autonomic leaning ability and application ability.

\section{Theoretical Basis}

MOOC is a kind of massive open online courses, which is diverse in course content, high in quality, a delicate pattern model on study science. Compared with traditional classrooms, MOOC is more developed in number of class students, time, and communication and so on. Flipped Classroom or Inverted Classroom is also a platform on the internet, which encourage students watch teaching videos and relative materials off the class initiatively, for acquiring good education resource. And it change traditional teacher-student roles for students do not receive the knowledge passively but get it online actively while teachers do not teaching the language points mainly but emphasize on answering student's question and directing their learning.

Salman Khan established Khan Academy in 2007, and its offer teaching videos, online exercises, and online assessment and so on to put forth the practice of MOOC and Flipped Classroom. Singapore government had stepped up Flipped Classroom fully early by transferring students to autonomic learners. The University of Queensland in Australia systematically researched how to enhance students' superior mind with more time, such as Bloom taxonomy analysis, comprehension and evaluations.

Chen Jining, the president of Tsinghua University believes that MOOC provide a new spreading way and learning style of knowledge which may trigger a very significant reform of global high education. Daphe Koller of Stanford University thinks that Flipped Classroom is the greatest one 
after classroom teaching model since European Renaissance. However, Both MOOC and Flipped Classroom have prominent advantages as well as disadvantages obviously. Kang Yexin[1] refers to seldom interactive and communicative aspects of MOOC, with impossible individual learning and evaluation of learning results, hence the crisis of quality and low completion. Lu Qiang[2] also say about the subtler effect of flipped classroom in some practice because that the low qualities of video designing and producing, and activities on class. Therefore, more and more teachers and scholars tempt to combine the two. American experts Jarrett mentioned that in San Jose State University students are allow taking MOOC as homework while encouraged to solve deeper issues and questions on class. Zeng Minxing[3] came up with setting a field integrated with context, communication, experience and reflection by combing MOOC and Flipped Classroom. Hu Jiehui[4] carried out many experiments to prove that only by realizing the flipped teaching from input to output on MOOC in teaching formation, and class formative evaluation on MOOC, can realized it the teaching target.

\section{On Learning Model in MOOC and Flipped Classroom}

Autonomic Leaning. Autonomic is a self-management ability focusing on attitude, competence , and environment, with increasing cognition and role or attitude transformation. With modern teaching methods, especially modern education technologies based on the Internet, it requires that students should have considerable autonomic capacity [5]. According to the condition of our college students in English, the specific pattern of autonomic learning is as follows: the first step is that teachers make videos or make use of current MOOC resources, and require students to watch corresponded videos before the class. Then students primarily finish assignment and put down the difficulties. The third step is that in form class teaching, the teachers and students conduct the interaction, asking and answering, which can advocate students all the impossible learning ways such as individual thinking, self-study and experiments. On the class, the main task of teachers turn into directing students to explore, answer, and reflect, in which the autonomic learning ability of students have been improved unconsciously.

Cooperative Leaning. It refers to more than two learners who carry out a series of activities as an unit for mutual learning goals, by means of Internet and so on, with various methods, which highlights positive interactions between students and team cooperation, enhance students cognition, cultivate cooperative spirits of college students.

Of course, the responsibility of teacher under such a model is more important. Firstly, teacher should consider the habits, of students' discussion, their will and differences or similarities as well their grades, genders, characters and so on. Then, teachers have to make the rule and discipline of cooperative learning, guaranteeing the running of the community and mutual experience as the community members, for instance, some activities such as contests or seminars are organized regularly to strengthen community learning atmosphere. Besides, surveys are conducted to know about students' mutual prospects and reflection for adjusting to the cooperative learning. Furthermore, teachers are required to encourage students to participate in this model, strive to treat students as individuals and to help each one to achieve their full potential. Putting forth the elements of emotional factors and effects, they establish the humanized environment for learning and manage the learning of the whole class to maximize the whole learning results.

Mix Leaning. Based on the above two learning model of autonomic and cooperative ones, the paper is about to integrate the two learning models, and put the mix learning model into practice teaching, in which the Flipped Classroom teaching based on MOOC combines face to face teaching and online learning, integrating autonomic and cooperative learning model, aiming to initiate students learning motives and consciousness, foster their autonomic learning abilities. This mixed learning model includes diverse learning pattern with various teaching resources such as class learning, autonomic learning, group learning, language skill practice and so on, all of which get together to form a complete teaching and learning[5]. Applying the online learning and class learning are beneficial for the realization of the course target. 
Feasibility Study. As provincial university, our College English Reform have been more than ten years, during the period, many excellent teaching concepts and methods have been applied to audio-visual-speaking course on the Internet and its relative on-off line monitoring. All the experience and facilities provide the new teaching model with excellent resource and platform. It mainly includes three aspects. The first one is the College English audio-visual-speaking platform, which can provide MOOC and Flipped Classroom with enough online learning resources and interactive platform. Teachers are responsible for making videos and collect MOOC videos and upload, arrange pre-class homework on Flipped Classroom, besides, the feedback after class, group learning and common discussion can be carried out on the platform. The second is that the Internet and Pigai.org, after a period of practical teaching, the writing exercises and instruction by the website is very important for writing teaching, for existing questions in students' writing, teachers can make systematically analyze and research. Furthermore, the APP also monitor students' fulfillment of schedule, and timely and effective interaction. The third is that Weixin, the most propular communication tool now, of which the group setting up can supervise students' learning, introduce teaching evaluation and survey according to different learning aims. Collecting and accumulating statistics may help us make analysis according to the Internet and further study on the topic.

Model Constructing. MOOC and Flipped Classroom transfer teachers' authoritative roles, which highlight knowledge internalization, and is a totally new, students-centered learning style. In the paper, the mathematics majors of Class 1, Grade16 are chosen as the test group, and Class two as the comparative group. The test group will be taught under the new model of MOOC and Flipped Classroom with mixed learning styles of autonomous and cooperative learning, integrated with face to face teaching interaction off line and online learning, for forming Interactive stereo flipped class in college English teaching. According to the satisfying and formative assessments of students, scientific evaluation system could be established to optimize the teaching and draw the relative conclusion[6].

Since MOOC and Flipped Classroom overwhelm the traditional teaching in class and knowledge internalization, and its model constructing has three key points as follows:

At first, reasonably and scientifically arrange the teaching objectives and tasks before the class. Not only drawing on the experience of Khan Academy where micro-videos are made in online open courses for students learning before class. It also makes full use of College English audio-visual-speaking platform, which offers all kinds of videos, leaning, exercises, quizzes, and assessments, play an important part in teaching. On the other hand, teacher can make and record video according to own requirements and teaching content. Owing to students' autonomy to greater degrees, it requires teachers to strengthen communication with students and contact students timely, to make autonomic learning schedule, organize students sign the assignments, and check the homework of students as the schedule of assignments, monitoring students learning with communication software's and answering questions on the class discussion of the platform and online as soon as possible.

Secondly, delicately organize the claws activities. The key of the paper test is about practical teaching to the test class. The new model means more teaching practices, including class quiz, group inquiry, communication or discussion in partners or group team, one to one individual guide and so on. It varies from the Listening and Speaking to Reading, similarity, what teaching activities will be taken depend on what the content of intensive Reading courses are. With the teaching objectives teachers set and design discussing topics and instruct students to think independently, participate in that imitatively and cooperate with team members, finally they make comprehensive conclusion and answering the questions. According to practical teaching activities, teachers can find out the problems of students in common, so solve the problem timely and feedback on that can help optimize the teaching contents and forms. Autonomic and cooperative attitude run through the whole course and teaching, which is helpful for students' initiative cultivation. 


\section{Teaching Evaluation of Learning}

Teaching evaluation, as the standard of teaching objectives, carries out relative judgment and value assessments to teaching course and teaching results by scientific evaluation methods, which generally includes the evaluation on teachers, students, teaching strategies in the course and the most important one is the evaluation on learning effects of students and teacher's teaching.

The study on Flipped Classroom and MOOC is the beginning in China, so the relative theoretical research is not too much especially on evaluation. However, teaching evaluation is too far important for information feedback of MOOC and Flipped Classroom teaching. Only by supervisory control of teachers and students on and offline teaching and learning, can teacher get timely and first hand information and feedback of teaching, and can they know about the gains and loss, weaknesses and strengths in the flipped teaching, and can they finally reflect and improve. Meanwhile, the students also can know more about themselves and their conditions or level of learning from the evaluations, by changing and adjusting for better study. Therefore, the evaluation is vital to identifying the class teaching.

Learners Satisfying Measurement. It's a very significant element for Flipped Classroom teaching evaluation. Comprehensive evaluation of factors here is applied to analyze students' satisfying during the whole course.[8] Based on the survey on the platform, the result show that students have relative more interest in the new teaching model, plus, they are satisfied with mixed learning and learning measure means, and approve of considerable improvements to a greater extent in all aspects.

Conprehensive Measurement. The current teaching evaluation is based on Fourth generation of evaluation on Subject pluralism, comprehensive content, equal evaluating relationship, various measurement methods and so on. Taking the consideration of College English teaching features, by Influence factor analysis of learning satisfaction, using the formative evaluation as the means, on the basis of teaching evaluation references, the paper is to combine fuzzy set theory and analytic hierarchy process to determine all the reference and their weights, finally passing through the consistency check, effectively enhance the teaching.

\section{Conclusion}

Undoubtedly, scientific and reasonable learning models constructing and teaching evaluation establishing in the Flipped Classroom on MOOC can exert teacher's main leading role and students' initiatives and creation, and the ultimate objectives of the new teaching model is not only to improve students' English comprehension and self-study abilities, but cultivate more talents with better English capacity for Our provincial economic sustainable development.

\section{Acknowledgements}

Social Science Project of Jilin Province Department of Education "13th Five - Year", Model of Flipped Classroom on MOOC in College English Audio-visual Course. Project No. JJKH20170088SK.

\section{References}

[1] Y.X.Kang: An analysis on SPOC - post-MOOC Era of Online Education [J]. Tsenghua Journal of Education, Vol.2014 35(1):85-93

[2] Q. Lu: The reflection on Flipped Classroom [J]. E-Education Research, Vol.2013 (8):91-97

[3] M.X. Zeng: From MOOC to SPOC: Construction of a Deep Learning Model [J]. Modern Distance Education Research Vol.2016, 26(1):41-49

[4] J.H.Hu: An Empirical Study on the MOOC-based College English Flipped Classroom Instructional Model [J]. CAFLE Vol.2014 (6):40-45

[5] L. Li\& P.H.Sun: Report on Various Learning modes of College English [J]. Foreign Language World, 2014, 24(3):71-78 
[6] M. Tang: MOOC Revolution [M]. Beijing: China CTTIC Press, 2015:40-46; 70-78

[7] Jonathan Bergman \& Aaron Ssams: Flipped learning: Gateway to Students Engagement [M]. International Society for Technology in Education ISTE 2014: 147-151

[8] S.M. Wang, \& L. X. Zhang: A Study of College EFL Learners' Acceptance Towards Flipped Classroom [J]. Modern Education Technology, 2014, 24(3):71-78 